\title{
QUYSC STEM Digilearning Model
}

Nitha Siby, Enas Elhawary, Jolly Bhadra, Noora Al-Thani

Qatar University Young Scientists center (QUYSC), Qatar University

\section{ABSTRACT}

Covid 19 and the unprecedented shift in educational delivery, has revealed multiple perforations in the science learning pedagogies. The technological replacements for a physical presence of an instructor and peer learning pedagogies. The technological replacements for a physical presence of an instructor and peer collaborated classroom could not retain student interaction and positive learning attitude as in the pre-covid
period. YSC STEM Digilearning Model, is an online voluntary summer course that was created to combat the respective hitches and was successfully implemented on 38 primary- preparatory students from diverse schools promising an active learning environment. Student Feedback mechanism approach was implemented throughout the course thereby providing voice to the students in the learner centered approach adopted by the STEM course. The course carried out diverse synchronous and asynchronous activities with positive student response as the study witnessed minimal student withdrawals and presentation of completed student assignments.

\section{INTRODUCTION}

The impact of online learning was previously investigated on higher education students, on the contrary, it was not widely implemented for K-12 learners. The conclusions from studies conducted by prominent researchers on effectiveness of virtual science classrooms as mentioned below, led us to create a path breaking solution.

- Virtual learning interaction assisted the students in improving their overall development in terms of social Virtual learning interaction assisted the students in
acceptance and learning outcomes (Yu et al., 2010).

Students prefer direct participation as in a synchronous session that incorporates effective interaction and technical ease, course scheduling and innovative communication strategies for enhanced student engagement (Banna et al., 2015).

A cohesive and interactive environment inclusive of group-based activities, assignments, and productive feedbacks are quintessential for success (Gayton and McEwen, 2007).

Meaningful learning through efficient communication opportunities aid students with course engagement despite the deficit of a physical presence of facilitator or a school classroom.

\section{RESEARCH OBJECTIVE}

The research team designed and implemented a course, especially for middle school to combat the following shortcomings in interaction of students on a virtual platform.

- Better student engagement through hands on activities

- Effectively build learning arena with peer collaboration space

- Efficiently create scientific lab spaces at student homes through the customized science based course material. - Include both synchronous and asynchronous activities like real time course session, meeting chats, real time educational games, live presentations, poster seminars etc and exploring learning videos, assignments like hands on scientific experiments, group discussions etc respectively in proper proportions.

\section{METHODOLOGY}

The STEM course was designed for the 38 primary-preparatory students, 24 girls and 14 boys, from 7 different public and private schools in Qatar with a transparent and concise objective of overcoming the existing public and private schools in Qatar with a transparent and concise objective of overcoming

- The participants are mentored by University Under graduate students for better understanding.

The online STEM course has implemented a well structured course framework that carry out both synchronous and asynchronous activities.

Synchronous activities are carried out on real time $1 \mathrm{hr}$ sessions for 5 days and asynchronous activities are assignments that are completed as homework with the assistance of parents.

- The content for 1- week course is based on science topic, Forces and motion, as per the standards outlined by Qatar Science Curriculum (QSC) for grades 5, 6 and 7 as shown in Figure 1 (b).

- By the end of the course, the students successfully engineered a product as a result of the course.

(a)

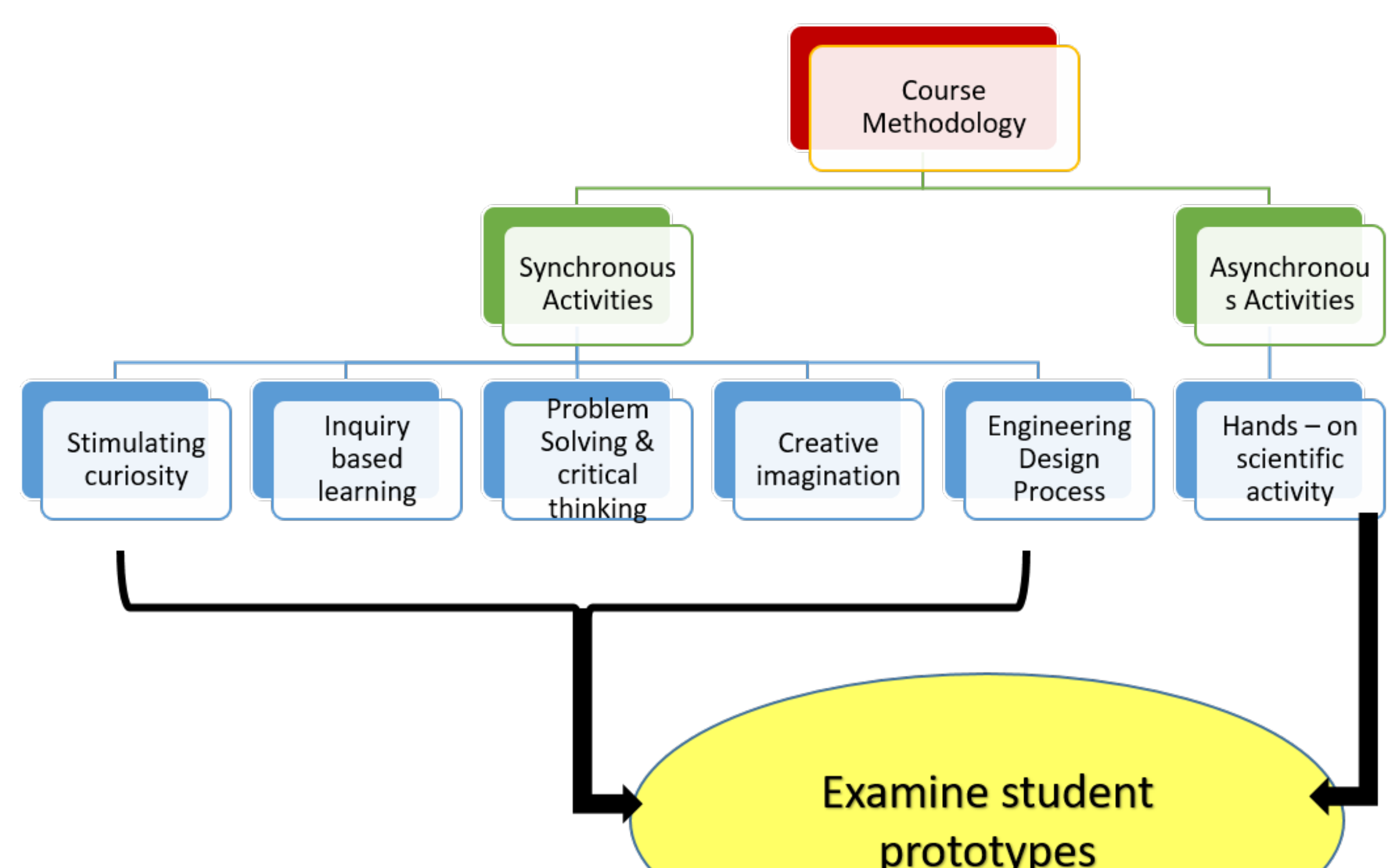

(b)

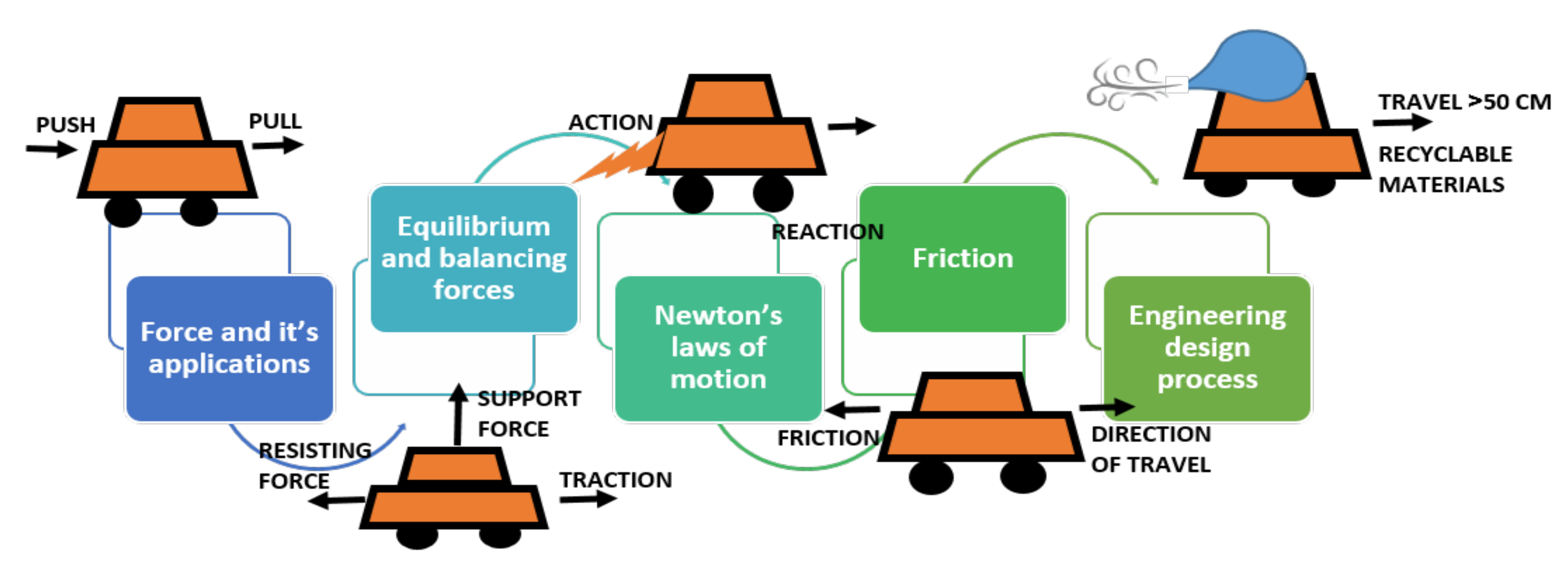

Figure 1 Research design for the methods adopted for the study. (a) The framework shows the of synchronous and asynchronous activities based on the content. (b) The course learning

\section{REFERENCES}

- Banna, J., Lin, M.-F. G., Stewart, M., \& Fialkowski, M. K. (2015). Interaction matters: Strategies to promote engaged learning in an online introductory nutrition course. Journal of Online Learning and Teaching 11(2), 249-261.

Gayton, J. and McEwen, B.C. (2007). Effective online instructional and assessment strategies. The American Journal of Distance Education, 21(3), 117-132.

Yu, X., Zhang, M., Xue, Y., \& Zhu, Z. (2010). An exploration of developing multi-touch virtual learning tools for young children. 2010 2nd International Conference on Education Technology and Computer,

\section{RESULTS \& DISCUSSION}

The result of the objective was accomplished by witnessing students' active participation with minimum withdrawals as they participated in variant synchronous activities that implemented simulations, games and activities.

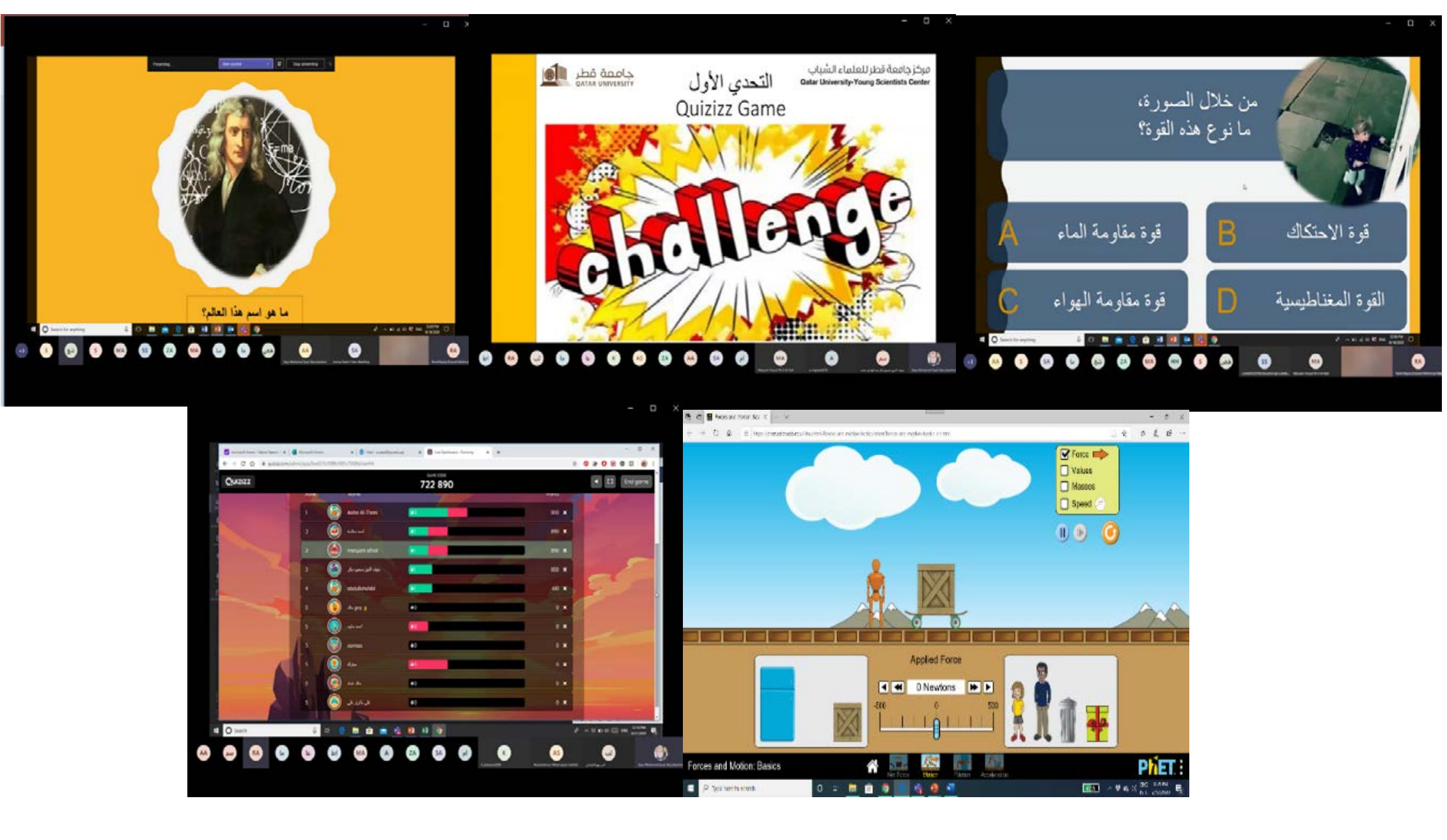
for minimal withdrawls

The participants also constructed labs at home so that they participate in asynchronous activities as shown in the Figure 3.

Students exhibited enhanced teamwork through the online communication on social platforms like WhatsApp and MS teams

The experiments were conducted with easily available materials like Clothes hanger, Plastic cups, Rope, paper, plastic bottles, and bottle caps etc. guaranteeing material access to every student at home as in Figure 3.

The design project activity, included in the course, was the key highlight of the workshop in

- student creativity, problem solving, reasoning potentia

The criteria followed while making the design project were,

- A car should be made from using recyclable materials

- The car should cover a specific distance $(50 \mathrm{~cm})$.

The car should move on different surfaces under balanced forces etc., to pass successful thereby testing their competitiveness.

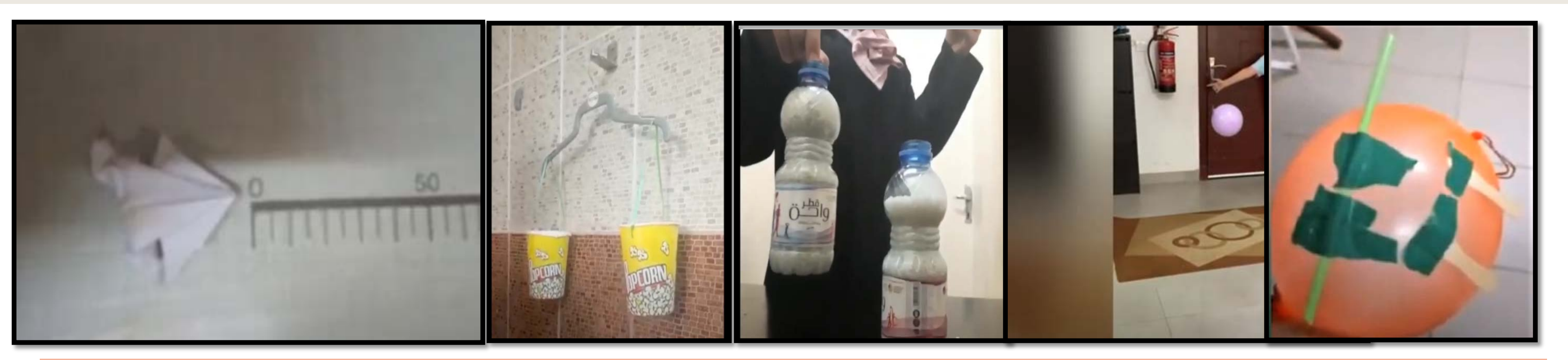

Figure 3 . Results documented as images from the diverse asynchronous activities that are carried out

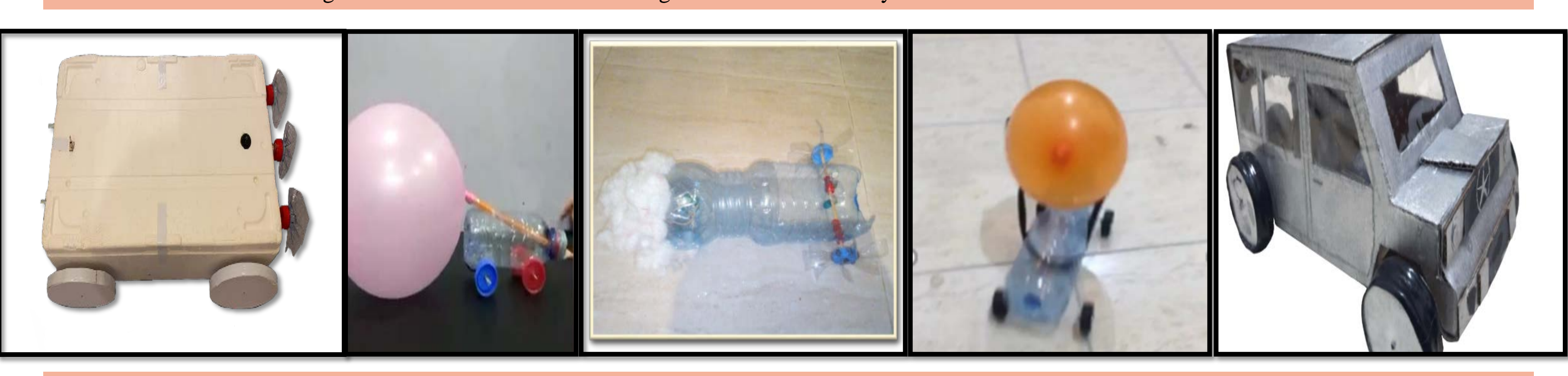

Figure 4: products made by students by the end of the workshop as a part of engineering design challenge

The effectiveness of the course was assessed by the results from feedback mechanism implemented in the daily session.
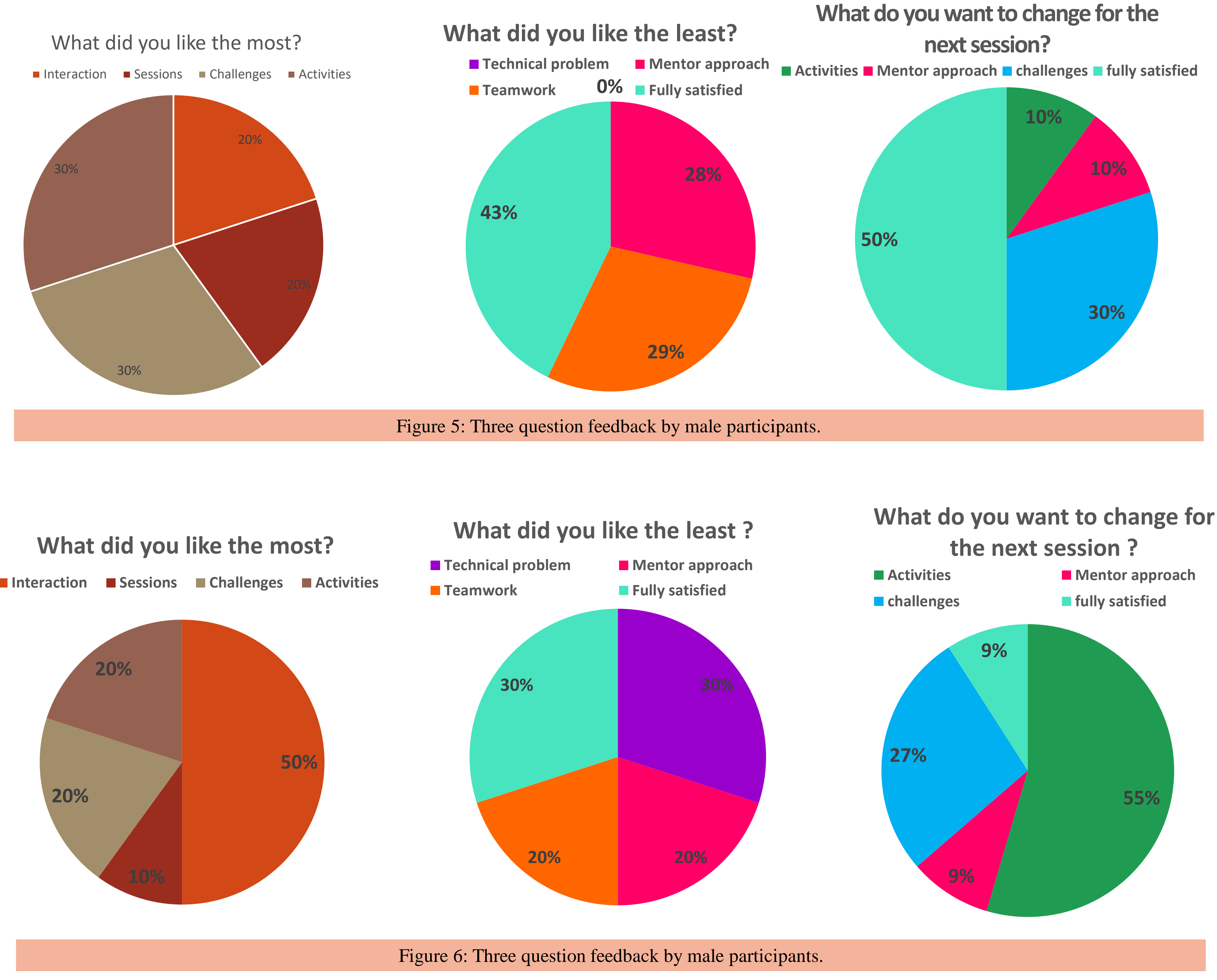

Figure 6: Three question feedback by male participants.

\section{CONCLUSION}

This paper elaborates on creating a STEM-based virtual course aimed at compensating the deficits of virtua classrooms through various teaching tools, both digital and traditional, hands-on experiments, assignments. The 38 participants exhibited various levels of competence by successfully performing the distributed tasks and participating actively in the student-centered learning approach. They engaged in the course instructional delivery through daily feedback. The facilitators of the workshop consistently improved their teaching approach in concluding the course material to be successful with the following features;

- Sound course design should accommodate flexibility, interaction, and content creativity.

- Students' interaction is directly proportional to improvizing teaching strategies.

- Challenging peer-based activities can enhance communication.

Offering students with both synchronous and asynchronous course activities can retain students' attendance rate in similar courses.

\section{ACKNOWLEDGEMENTS}

Thanks to Qatar University, partners UNESCO and Qatar National Commission. 